
https://doi.org/10.30534/ijeter/2021/15942021

\title{
Development of two-wheeler towed emergency purpose trailer for rescue operation
}

\author{
A.Gowtham $\operatorname{Rajan}^{1}$, S.Gowthaman ${ }^{2}$, M.Sivasubramanian ${ }^{2}$,V.Sakthimurugan ${ }^{3}$ \\ ${ }^{1}$ Assistant Professor, Department of Automobile Engineering, School of Automotive and Mechanical \\ Engineering, Kalasalingam Academy of Research and Education, India, gowthamrajan16@ gmail.com \\ ${ }^{2}$ Associate Professor, Department of Automobile Engineering, School of Automotive and Mechanical \\ Engineering, Kalasalingam Academy of Research and Education, India, gowthammech@ hotmail.com, \\ msivasubramanian.prk@gmail.com \\ ${ }^{3}$ Assistant professor Department of Automobile Saveetha School of Engineering, Saveetha SIMATS, India, \\ sakthimuruganmtech@gmail.com
}

\begin{abstract}
Ambulances are designed for quick response of emergency cases and to take a level of care for patients. Ambulances types are classified into four types based on their facilities. They are type A, type B, type C, type D. Type A is first responder. Type $\mathrm{B}$ is patient transport vehicle. Type $\mathrm{C}$ is basic life support ambulance. Type $\mathrm{D}$ is advanced life support ambulance. This work falls under category of type B. Type B ambulance is used to carry patient. Current work plan is to implement some main medical kit which is similar to type $\mathrm{C}$ ambulance. The project purpose is to focus on rural people to connect nearest health centre in the town area during emergency cases. Construction of trailed ambulance design is based on to overcome the problem faced by four wheeled ambulances in rural area. Also, the concept is based on to reduce death rate in village area and comfort ride in traffic places. Manufacturing cost of the ambulance is drastically reduced and also it could carry a patient and main necessary medical kit. Full body covered with sheet metal and patient compartment trailer unit is coupled with bike chassis frame during emergency cases. Trailer clamp is designed with adjustable length and width. Bike is uncoupled with trailer compartment and free to use when there is no emergency case.
\end{abstract}

Key words: Ambulances, Two-wheeler Ambulance, Emergency Vehicle, Rescue Vehicle.

\section{INTRODUCTION}

An ambulance is a vehicle equipped to provide emergency care to injured people and to get them to hospital. Ambulance plays important role in emergency purpose. Ambulances is initial used in war field for injured soldiers later is changed to emergencies vehicle to people service. Ambulances services is still facing difficult to connect patients and hospitals. Several ways of ambulance are available in the world to safe guard the persons. Among this land way ambulance is mostly using all over the world. In India land and water are the two ways are mostly used for emergency transportation. India is the largest populated country in the world. Necessary of ambulance is increasing day to day. In India per year 1,50,000 persons killed in road accidents. Cardiac vascular diseases increasing every year in India. Connection of rural and urban areas are not proper in some places in India. Nearly $65 \%$ of Indians are living in rural areas. It is difficult task for ambulances to reach some village in India due to damaged roads, mini pathway. In cities due to heavy traffic ambulances face more problems to reach hospitals in emergency cases. Some reasons for poor services of ambulances due to low public awareness, inadequate emergency transportation infrastructure, and the lack of a coordinated emergency medical services. In India bike emergency service which provide first aid treatment and also sidecar attachment are introduced. The sidecar attachment carry only person and it not carry any emergency kit.

Balabin et.al[1] researched maternal mortal was more in the sub-Saharan Africa. This is due to poor transportation and delay in reaching in time. It was difficult to pay ambulance fees for poor families. Cost of the car ambulance is high and also maintenance and repair. So, Malawi government initiated the process of motorcycle ambulance in rural areas the research was discussed and planned with the District Health Management. The motorcycle ambulance is placed in three main health centres in district to reach quickly to the surroundings rural areas. Logbooks are used to record data. They recorded for one-year period of time. From the result it reduces the delay period and saves most of the lives. It is cheap, less maintenance and best compare to car ambulances.

Brylev et.al [2] says that Cardio vascular diseases is increasing every year in India. It is projected that at 2020 nearly $60 \%$ Indians have CVD (cardio vascular diseases) in world wide. ST segment elevation myocardial infarction (STEMI) and sudden cardiac arrest (SCA) are the two problems causes major death in India. This is due to delay in 
reaching in time to hospital. Some reasons low public awareness, inadequate emergency transportation infrastructure, and the lack of a coordinated emergency medical services. It was very risk for CVD persons to reach hospitals in high crowded area. So, motorcycle ambulance with driver and paramedic assist are introduced in India. They provide some precaution until ambulance reach. In India two-wheeler scooter are used because it is light in weight and easy handling for both men and women. They also provide safety equipment for drivers. Paramedic is trained and able to handle all equipment to find CVD in patients. Main to reduce death due to delay. So, this method helps to patients for initial state sustain for some period of time until the high facilities cardiac ambulance reach. Paramedic carry drug, defibrillation etc.

Dezhurny et al [3]. says most peoples in India going to death due to non-availability of quick and good quality of emergency medical support. Government of India identifies the benefits of involving private persons under the National Rural Health Mission (NRHM) in public private -partnership model. The initial success of pre-hospital care services under Emergency Management Research Institute (EMRI) has further boosted the confidence of policy maker. In this study we present an assessment of the impact of EMRI services in state of Goa based on all the emergency reported. They using life saved data from pre-hospital records these can be effective of emergency and achieve a many life saved in good condition. They are handled towards through saved nearly in $43,835,31 \%$ trauma related and $8.12 \%$ of cardio vascular emergency. This emergency service is given utilization and satisfaction with the services. The EMS can lead the national wide treatment, transport and disaster management.

Evtiukov et.al [4] Its main role of determining the prognosis of victim to mainly important of urban areas in more traffic and rush places. These systems were in Portugal and is run by non-government organization. It has dispatch center, basic life support (BLS)units and advanced life support (ALS) each emergency call is received by a technician and send to dispatch center. Experienced and trained persons are used for the process. It carries equipment such as automated external defibrillator (AED), portable oxygen, basic airway management and trauma gear, stethoscope, capillary, glucose meter. This training for crew members 210 hours. This is useful for illness, trauma and other first aid process. It is quick and efficient for urgent situation.

Makarova et.al [6] says Norway three air ambulance is used to cover wide and sparsely populated region. It is operated day and night. It reaches the destination quickly. Cost investment in air ambulance is high. It is suitable for region like vast rural areas, mountain areas, long coastline, fjords. In western Norway nearly population 1,087,000 and covers an area
$45,000 \mathrm{~km} 2$. Western Norway area is high mountains, islands, fjords. Road are damaged in some areas in western Norway so response of ground ambulance is poor. The helicopters have standard capacity for patients, staffs, pilot, a rescue paramedic and an anesthesiologist.

Repin says Sensors, internet, smart technology places a major role in current days. Traffic plays main role for ambulance performance. By using these technologies, we can control traffic. Traffic is very more in cities area; it delays the time of ambulance during emergencies. Some simple traditional traffic managements are there that have light emitters that uses infrared and GPS for detecting the presence of ambulance and can also find the real time density of traffic. Radio frequency are used to find the position of ambulance. To determine traffic in area microwaves, infrared emitters, radar, ultrasonic image and video processing is used. VANET (vehicular ad-hoc network) are considered as effective system for communication between ambulances and traffic management system. This service is not only for ambulances but also for polices, fire emergency. This process is possible by IOT sensors, GPS, cloud. It helps to reach the ambulance destination point at correct time. It also tells the best and alternate route [7]. This system works on data from ambulances, software and data processing at cloud.

Simdiankin A. et.al says Madhya Pradesh is one of the states in India were lots of maternal morality takes place. Janani express in Madhya Pradesh is used to carry pregnant women. It runs 24X7. It is free of cost. It is launched I in 2006. It is a public - private partnership. It carries 60,000 patients per month. Name of the scheme was Janani Suraksha Yojana or safe motherhood scheme. This system is introduced to reduce maternal mortality. In world bank 2008 report mention that it prevents $75 \%$ of maternal death rate by reaching care unit on correct time in world wide. A total 893 vehicles operate under the JE in Madhya Pradesh. This scheme is mostly utilized by tribal and rural area peoples. Omni van are used to carry the motherhoods. It has problem in reaching in on time due to poor road conditions. Waiting for vehicles is a main drawback of this scheme [10].

\section{METHODS AND MATERIALS}

In Research of a concept on two - wheeler ambulance instead of sidecar attachment the plan was to introduce trailer attachment to carry the patients and emergency equipment. These systems help in rural and traffic area for easy reach from incident place to hospital. It is easier by hook the ambulance body with chassis of bike. This concept is never implemented till now, like that we took survey about this type of ambulance, but this idea is not discovered. Some are used motorcycle to carry only first aid kits. Bike carry medical kit to emergency spot and provide first aid until reaching of the ambulance. 
Another model is to carry a patient by using motorcycle with provided bed in sidecar of a bike. Mainly in this point we are noted and well analyzed to take the decision to make a good model based on a two -wheeler ambulance. After we are taking some plans to minimize the size of body compartment for easy riding in rural areas and traffic areas. This patient compartment model dimensions are taken in $(200 \times 100 \times 150)$ $\mathrm{cm}$. First step to find the problem in exist ambulance, problem faced by peoples and ambulance driver.

Process of fabrication and testing involves several processes. Initial find the root causes of poor ambulances services. Then to find necessary things required. After analysis of need and problem then finalizing the concept and developing the concept. Considering standards and constraints. Designing the project with software in $2 \mathrm{~d}$ and $3 \mathrm{~d}$. Materials purchasing for project such as tires, shock absorber, steel pipe, sheet metal, electrical components. Check the materials and matching tools follows the standard. After checking of standards initiating the fabrication process. After fabrication final step is painting. Then project is undergone test. If the test result is success it is used as an emergency vehicle or if the test result fails we have to study about reasons for failure. Alterative concepts and modification in design helps to overcome the failure.

As the product comes at reduced cost, it can be able to use by economically weaker people and this economic policy makes a main role of giving facility to all people. It is proposed to consider the economic constraint for the trailed ambulance work. The available rescue vehicles are not able to reach out remote areas and too expensive for the rural peoples. Cost of existing ambulance is so high. It charges more wages for travel from place to place. Hence it is proposed to design economically compact cabin with all first aid facilities.

Design for manufacturability is the general engineering practice of designing products. In such a way to easily manufacture a product, design must be laid strong without any defectiveness. The implementation of design differs widely depending on the manufacturing technology. In present design and fabrication work, a trailer type ambulance was designed, which has made up of steel pipe, steel sheets, flat steel bar and some materials. The ambulance patient compartment was manufactured in such a way to use it in two wheeled vehicles. The two wheeled vehicle carries all emergency equipment and perfectly designed for bike for easy riding. The front side of the body covered the laminated fibre glass. It contains tool box, area for medical things, and battery box. So, this patient compartment referred as to the manufacturability constraint. We had used standards in steel pipe are ASTM A500, that can be considered to HSS has a high strength to weight ratio, excellent compression support characteristics and excellent torsional resistance, so we could choose to give the good outcomes of the vehicle and chosen the welding is AWS D10.12 pipe welding this weld components can help the good quality to conjunction of strong each other. Hence it is proposed that in this work manufacturability plays a major role.

It is proposed to design the cabin with steel sheet to prevent from corrosion and environmental interactions. It is proposed to use ASME standards A1003/A1003M-15 (Standard Specification for Steel Sheet). A1030/A1030M-16: (Standard Practice for Measuring Flatness Characteristics of Steel Sheet Products) for selection of steel sheets for the fabrication of patient compartment [13-14].

AWS D10.12 pipe welding (mild steel), AWS D9.1 sheet metal welding. Welding standards for AWS A03.0, welding and allied processes. The mild steel of using rectangular pipe is ASTM A500 is a standard specification published by the ASTM for cold-formed welded and seamless carbon steel structure tubing in rectangular shapes. ASTM A36 standards for steel flat bar.

\subsection{Materials}

Materials are used for making a product. Materials has many properties they are physical, chemical, mechanical, thermal properties. For this work there are many materials needed to fabricate patient compartment they are steel pipe, flat bar, gear, nut, bolt, washer, shock absorber, wheel [5].

\subsection{Shock absorber}

It preserves the stability of the vehicle in pitching or rolling, while in motion. It provides comfort for patients and resist road shocks. Present st used Hero Splender rear shock absorber for four wheels. 4 independent shock absorbers are used. Material $=$ stainless steel, weight $=5-7 \mathrm{~kg}$, feature $=$ corrosion resistance

\subsection{Gear}

Gear setup is placed in the front portion of near medical kit box for turning purpose. Spur gear and rack are the two gears used for turning system. Spur gear is meshed with rack [15]. Spur gear moves in rotary motion and rack moves in linear motion. Rack will turn the wheel. Spur gear is used because of simple in design, economy of manufacture and maintenance. It is used at any speed. We used steel gear. It has high strength, toughness and tooth hardness. 


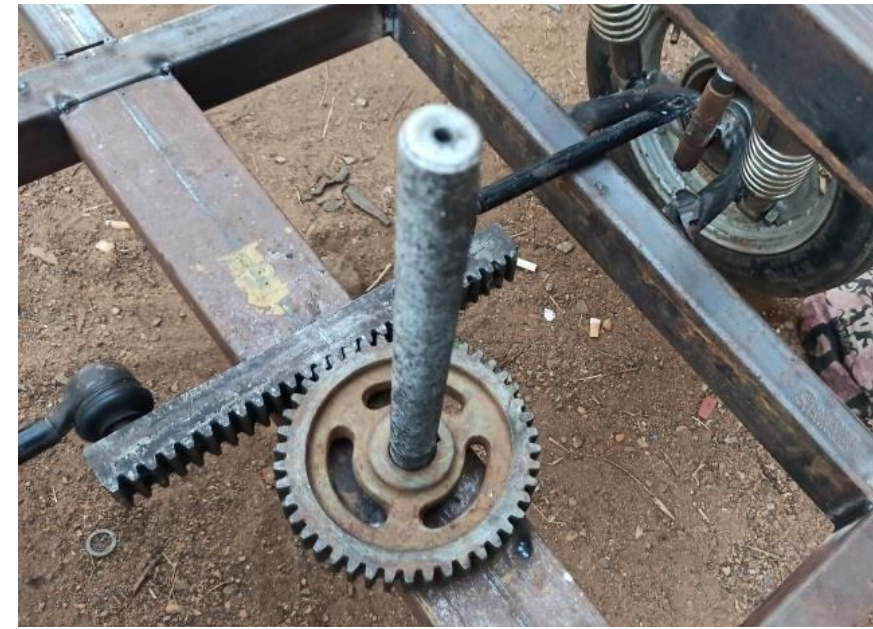

Figure 1: Spur gear \& Rack setup

\subsection{Tyres and rims}

A tyre is a cushion provided with an automobile wheel. It consists of mainly the outer cover i.e., the tyre proper and the tube inside. The type-tube assembly is mounted over the wheel rim. It is the air inside the tube that carriers the entire load and provides the cushion. Materials for tires are synthetic rubber, natural rubber, fabric, wire, carbon black and chemical compounds.

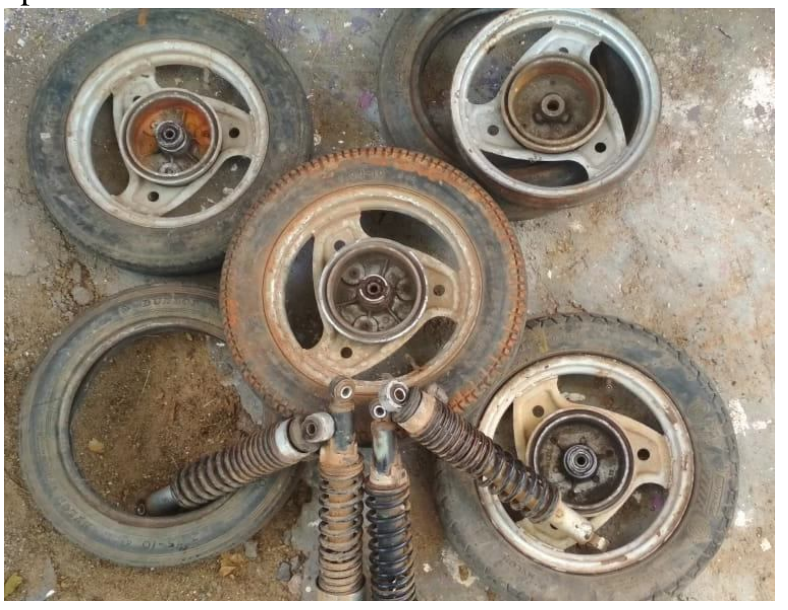

Figure 2: Tyre and rims

\subsection{Ball Joint}

Ball joint is moves in all direction. It provides safe and smooth ride. It is made up of bearing stud and socket enclosed in a casing. It is made up of steel. Stud is tapered and threaded. It is fitted into the holes of steering knuckle [8-9].

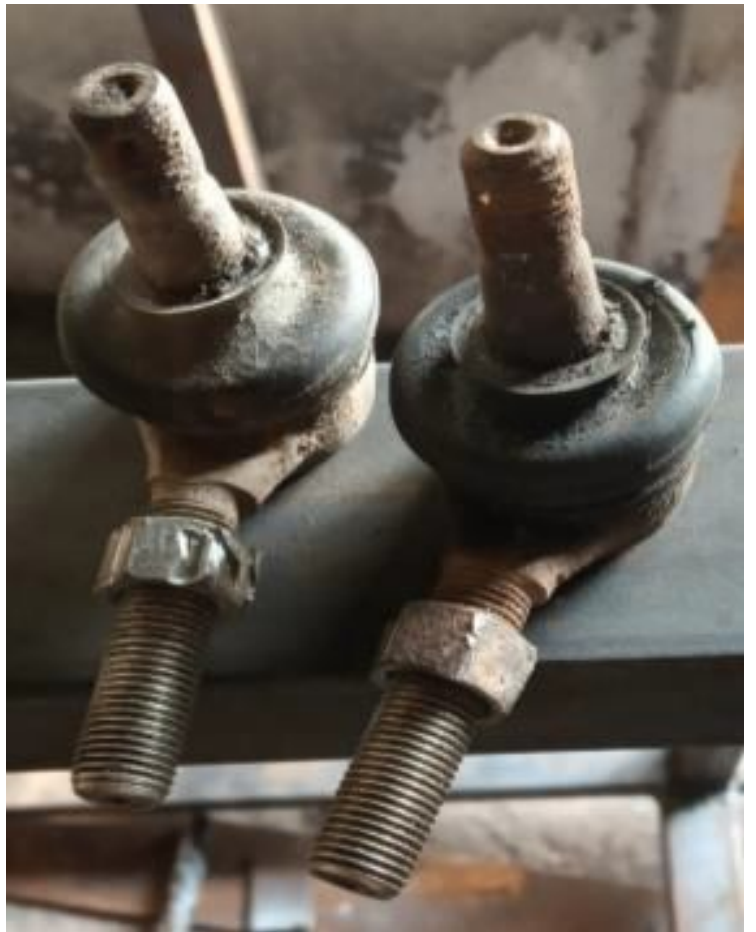

Figure 3: Ball joint

\subsection{Construction of chassis and patient compartment}

Materials such as rectangular hallow pipe is used for chassis construction. The chassis construction is conventional chassis frame. Chassis in ladder shape. Hollow section has high strength, high durability, strong, long life and more. After the completion of chassis frame, upper frame is fabricated. This project has two layer of frame area.

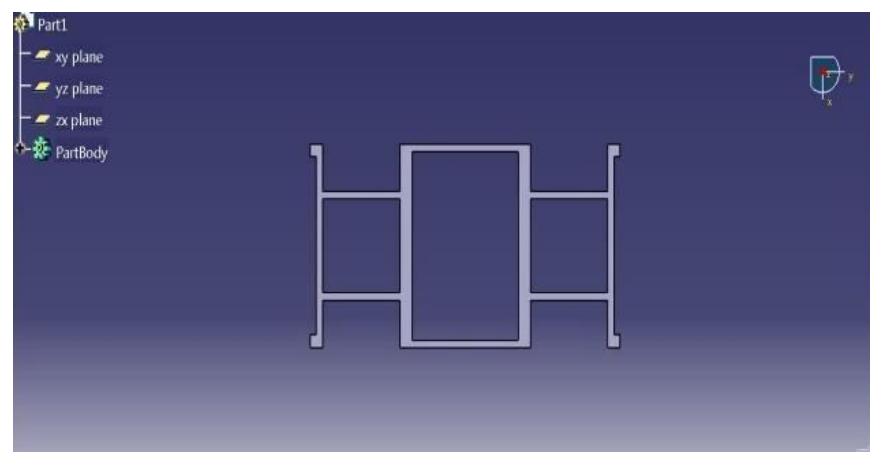

Figure 4: Chassis Frame (Catia Design)

Both the fame is joined by welding. Flat steel bar is used has fender in frame. Fender is used to cover wheels and it also safe guard from dust. The upper and lower frame has some gap. This gap is used as a medical kit storage area. In rear small portion is kept for battery box.

Circular steel tube is used for control arm. Shock absorber is mounted in control arm. shock absorbers another end is mounted in upper frame. Tire is fitted with linkages in the control arm. Four wheels are fitted. Each wheel is fitted 
independently. No shaft is placed between the wheels. All shock absorbers are connected independently.

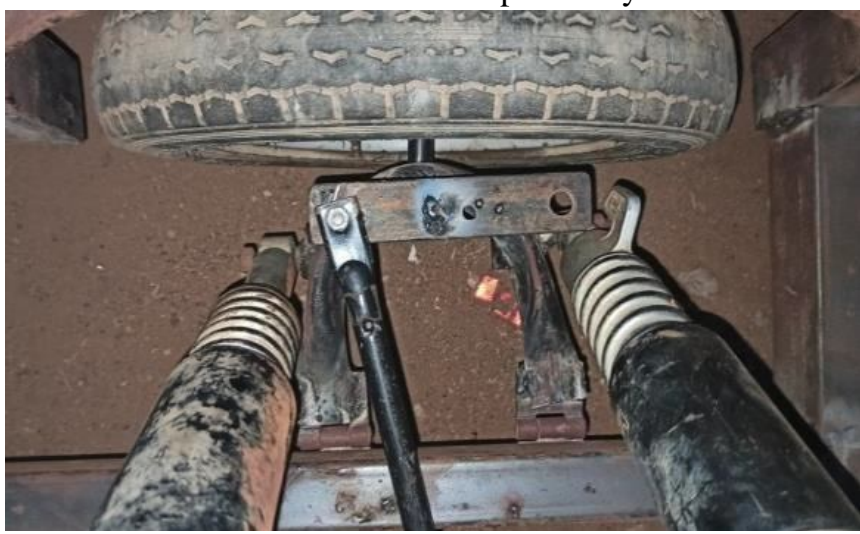

Figure 5: Shock absorber mounted on arm

After complication of this gear setup is placed. Spur gear is connected with clamp. Rack gear is meshed with spur gear. Rack gear end is fitted ball joint. Ball joints another end is fitted with knuckle joint with wheels.

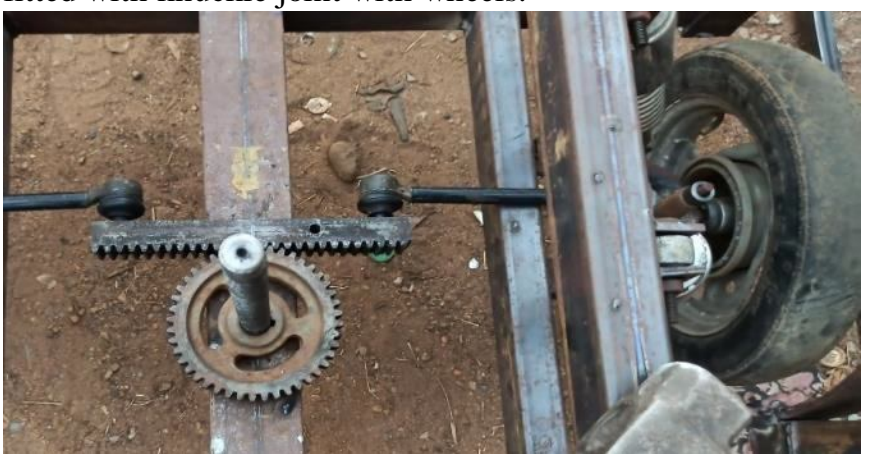

Figure 6: Spur gear connected to clamp

\section{RESULTS AND CONCLUSION}

The emergency purpose vehicle used for rescue operation and proposed the statement about vehicle was economic, so this can be used as all over area like as complicated road and uneven surfaces in the rural areas the vehicle dimension of the body is suited for this operation, we designed to serve the people who have struggled with no more facilities.

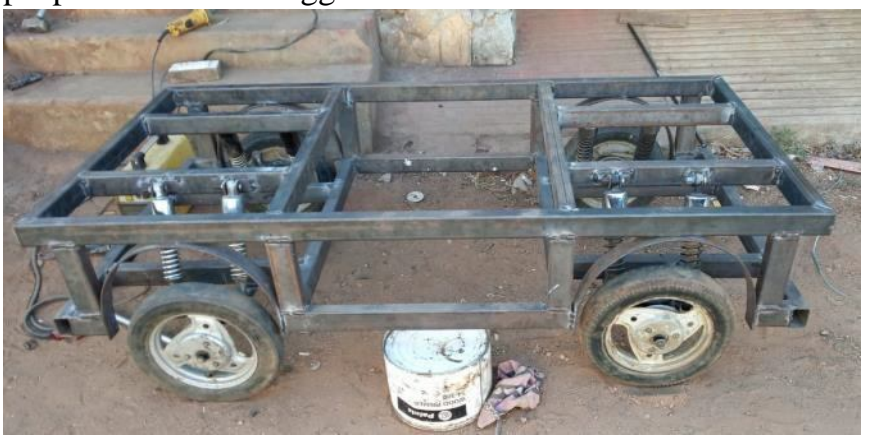

Figure 7: Chassis of Patient Compartment

This proposed product will be much helpful on the people and operations can do over some health risk factor of causing maternity, accidents and rescue on affected people this mechanism is designed on trailer attachment on carry to anyone of motorcycle, you see this factor it is easy to provide and save more life on the small dimensions compared on other vehicle, we hope that project will reduce mortality rate [11-12].

The product focuses the community on villages which has located on long distance to town so health problem if caused the vehicle can be use to departure at hospital on right time due to our quicker operation caused. If government decides to serve more ambulances to villages.

This ambulances construction is most suitable for emergency cases. To ensure that fundamentally cost is given on very less in user charge the vehicle has running on motorcycle attachment so this can be preferable to low charger on fuel, money and so many things etc.

Trailed ambulance is also helpful on factories, industry and school, colleges. When the health issues affecting people if lack on time to reaching the hospital is due to increasing death factors, so we finalized and proposed the necessary on vehicle in economic and compact sure enough to serve on people.

Fabricated vehicle was tested for performance, turning radius of patient compartment, at different speed the mileage, load capacity and coupling unit suitable for all two-wheelers. From the test result everything suited and well performed. Maintenance and running cost are low compare to other ambulances.

\section{REFERENCES}

1. Balabin, I.V., Bogdanov, V.V., Chabunin, I.S., The influence of the mass of the driver on the vibration endurance. Zurnal AAI 4 (93) 2015, 16-20.

2. Brylev, I., Evtiukov, S., Evtiukov, S., Problems of calculating the speed of two-wheeled motor vehicles in an accident. Transportation Research Procedia 36 (2018), 84-89. DOI: 10.1016/j.trpro.2018.12.047.

3. Dezhurny, L.I., Shuvalova, E.A., Lisenko, K.I., Baturin, D.I., Emergency system by the victim in road accident, as one of problems of traffic safety. In: Kravchenko, P.A. (ed.). Organization and Traffic Safety Management in large cities. Proceedings of the 9th International Scientific and Practical Conference. Saint Petersburg State University of Architecture and Civil Engineering, Saint Petersburg,2010, 93-95.

4. Evtiukov, S., Karelina, M., Terentyev, A., A method for multi-criteria evaluation of the complex safety characteristic of a road vehicle. Transportation Research Procedia 36, 2018, 149-156. DOI: 10.1016/j.trpro.2018.12.057.

5. Iyevlev, A.A., Kamyshnikov, A.I., Zolotukhina, T.V., 2014. First aid effectiveness improvement in road accident victims: legal grounds and possible legal consequences. Vestnik of Voronezh Institute of the Ministry of the Interior of Russia 4, 2014, 259-268.

6. Makarova, I.L., Analysis of methods for determining the weighting factors in the integral indicator of 
public health. Symbol of Science, International Journal 7, 2015, 87-94.

7. Repin, S., Evtiukov, S., Maksimov, S., A method for quantitative assessment of vehicle reliability impact on road safety. Transportation Research Procedia 36, 2018, 661-668. DOI: 10.1016/j.trpro.2018.12.128.

8. Bastida, J.L. et al., The Economic Costs of Traffic Accidents in Spain. Journal of Trauma, 56(4), 2004, 883-888.

9. Garcìa Altés, A. and Pérez, K., The Economic Cost of Road Traffic Crashes in an Urban Setting. Injury Prevention, 13(1), 2007, 65-68.

10. Simdiankin A., Byshov N., Uspensky I. A method of vehicle positioning using a non-satellite navigation system. Transportation Research Procedia. 2018. p. 732-740.

11. Voytko, A.M., 2020. Method for calculating the speed characteristics of a single-tube shock absorber. Bulletin of Civil Engineers 2 (79), 2020, 168-172.

12. Dobromirov, V.N., Voytko, A.M., The impact of the ambulance vehicle mobility on the efficiency of using the "golden hour" in metropolis conditions. Bulletin of Civil Engineers 6 (77), 2019, 290-298.

13. Kerimov, M., Safiullin, R., Marusin, A., Marusin, A., Evaluation of functional efficiency of automated traffic enforcement systems. Transportation Research Procedia 20, 2017, 288-294.

14. Leskin, A.I., Katasonov, M.V., Gofman, D.I., The method for simulating the passage of speed bumps of the roadway with consideration of dynamic factors. Bulletin of Volgograd State University of Architecture and Civil Engineering. Series: Construction and Architecture 2 (75), 2019, 92-100.

15. Marusin, A., Marusin, A., Danilov, I., A method for assessing the influence of automated traffic enforcement system parameters on traffic safety. Transportation Research Procedia 36, 2018, 500-506.

16. Pushkarev, A., Podoprigora, N., Dobromirov, V., Methods of providing failure-free operation in transport infrastructure objects.Transportation Research Procedia 36, 2018, 634-639. DOI: 10.1016/j.trpro.2018.12.140. 